\title{
Lung Health in the Solomon Islands: A Mixed Methods Study
}

\author{
James Di Michiel (1D' \\ Julie Gawthorne ${ }^{2}$ \\ Aruna Shivam ${ }^{2}$ \\ Kevin Maruno ${ }^{2-4}$ \\ Sarah Cohn ${ }^{3,5}$ \\ Christopher Lemon ${ }^{3,6}$ \\ Zhixin $\mathrm{Liu}^{7}$ \\ Anthony Byrne ${ }^{1,3}$ \\ 'Department of Thoracic Medicine, St \\ Vincent's Hospital, Sydney, NSW, 2010, \\ Australia; ${ }^{2}$ Department of Emergency \\ Medicine, St Vincent's Hospital, Sydney, \\ NSW, 20I0, Australia; ${ }^{3}$ University of \\ New South Wales, St Vincent's Medical \\ School, Sydney, NSW, 20I0, Australia; \\ ${ }^{4}$ University of Notre Dame, St Vincent's \\ Medical School, Sydney, NSW, 20I0, \\ Australia; ${ }^{5}$ Department of Psychiatry, \\ Prince of Wales Hospital, Sydney, NSW, \\ 203I, Australia; ${ }^{6}$ Department of \\ Psychiatry, St Vincent's Hospital, Sydney, \\ NSW, 2010, Australia; ${ }^{7}$ Mark Wainwright \\ Analytical Centre, University of New \\ South Wales, Sydney, NSW, 2052, \\ Australia
}

Background and Objectives: Despite a population of 600,000 people from 900 islands, there is little published data on the prevalence of lung disease in the Solomon Islands. We sought to 1) estimate the prevalence of obstructive lung disease (OLD) in Gizo, Solomon Islands, 2) identify risk factors for respiratory disease in this population and 3) review current management practices for respiratory disease through an audit of local emergency department (ED) presentations.

Methods: A two-part mixed methods study was performed between March and May 2019; the first was a population-based, cross-sectional study conducted in Gizo, Solomon Islands, with a random sample undergoing questionnaires and spirometry. The second was an audit of Gizo Hospital ED records to assess presentation numbers, diagnoses and outcomes.

Results: A total of 104 patients were randomly selected for spirometry. The mean age was 46.9 years. Current smoking rates were high $(24.0 \%$ overall, $43.3 \%$ age $<40,16.2 \%$ age $\geq 40)$ as was regular ( $>10 \mathrm{~h} /$ week) exposure to indoor/enclosed wood fire ovens $(51.5 \%)$. The prevalence of COPD was $3.2 \%$ overall. A further $9.7 \%$ of participants demonstrated significant bronchodilator responsiveness suggestive of possible asthma. Most patients seen in ED presented with a respiratory condition or fever/viral illness, but spirometry was not available. Only four outpatients were prescribed salbutamol and two patients inhaled corticosteroid.

Conclusion: There appears to be a high burden of obstructive lung disease in the Solomon Islands with high smoking rates, indoor smoke exposure and bronchodilator responsiveness. Respiratory symptoms are common amongst hospital ED presentations; however, inhaled asthma treatments are infrequently prescribed to outpatients.

Keywords: obstructive lung diseases, COPD, asthma, inhalational exposure, Pacific Islands

\section{Introduction}

Despite a population of over $680,000,{ }^{1}$ there is little published data on the prevalence of lung disease in the Solomon Islands. It is estimated that currently $37 \%$ of the Solomon Islands population are actively smoking. ${ }^{2}$ Furthermore, smoke exposure from indoor wood fire ovens is thought to be very common in both regional and rural settings across the country. ${ }^{3}$ These exposures, as well as previous respiratory infections including tuberculosis, ${ }^{4}$ can cause permanent lung function impairment. As such, the people of the Solomon's are at risk of chronic respiratory disease. However, there are no recent studies using objective measures of lung function (spirometry) to assess the effect of these exposures on the lung health of people living in the Solomon Islands.

The Solomon Islands consist of six major Islands and over 900 smaller Islands. The country is divided into nine provinces with the capital city of Honiara, in Guadalcanal
Correspondence: James Di Michiel Department of Thoracic Medicine, St Vincent's Hospital, 390 Victoria Street, Darlinghurst, Sydney, NSW, 20I0, Australia

Email james.dimichiel@health.nsw.gov.au 
Province, comprising 84,500 people. Healthcare in the Solomon Islands is provided by seven provincial hospitals and one National Referral Hospital, working in conjunction with more remote Area Health Centres and Rural Health Clinics. ${ }^{5,6}$ The country's largest hospital, the National Referral Hospital in Honiara, acts as a referral centre for the small number of Provincial Hospitals and health clinics throughout the country. Our study took place in Gizo, the capital of the Western Province situated on Ghizo Island with a population of $\sim 6100$ people. Gizo Hospital is the second largest hospital in the Solomon Islands and was recently rebuilt in 2011 through grant aid from the Japanese Government. The hospital provides essential inpatient medical and surgical care to Gizo and surrounding islands. There are a limited number of outpatient medical clinics which are nursing led. At the present time there is no outpatient respiratory health service in Gizo or the surrounding islands. The aim of this study was to estimate the prevalence of obstructive lung disease among the general population of Gizo, Solomon Islands using pre- and post-bronchodilator spirometry and standardised definitions of COPD and bronchodilator responsiveness. ${ }^{7,8}$ Secondary objectives were to (a) assess the prevalence of known respiratory risk factors including cigarette smoking and bio-combustible fuel exposure (indoor air pollution), (b) explore the effect of age ( $<40$ years and $\geq 40$ years), body mass index and betel nut chewing on lung function, and (c) perform a review of current management practices and prescribing of essential respiratory medications in both a hospital and outpatient setting.

\section{Methods}

We performed a mixed methods study in two parts. Ethics approval for the study was obtained from the local institutional review board (IRB) equivalent of Gizo hospital, Solomon Islands. The study was conducted in accordance with the Declaration of Helsinki Ethical Principles for Medical Research Involving Human Subjects.

\section{Part I. Population Based Prevalence Study with Questionnaire and Spirometry}

A population-based, cross-sectional study was performed in Gizo, Solomon Islands from May to June 2019. All participants (or their parent or guardian) provided informed, written consent prior to participation in the study. Participants were assessed at two sites - the local Provincial Hospital (Gizo Hospital), including inpatients and visitors, and the local food and goods market on market day (the time when most of the island population visits). Sampling was performed at random from two clusters, 1) the general community and 2) local hospital with a ratio of 9 to 1 , with the objective of being representative of the Ghizo Island population. At the hospital site patients and visitors were selected at random as they presented to either the emergency department or during their stay on the inpatient ward. Sampling in the community setting involved setting up a stall outside the entrance to the weekly island market. All adults and children (over the age of 5 years) were encouraged to participate in the study and study personnel were available from $8 \mathrm{am}$ until $7 \mathrm{pm}$ at night to ensure ample opportunity for all members of the community to be selected. Participants were included if they were above the age of 5 years, able to perform spirometry without contraindication and provide informed written consent (or their parent/guardian for those under 18 years of age).

\section{Data Collection}

Participants completed a health questionnaire explained and administered by one of the investigators to eliminate literacy barriers to participation. Information collected included demographic data, medications, hospital presentations since 2018, smoking status, indoor wood fire exposure, previous respiratory and other medical diagnoses. Information on the chewing of betel nut was also collected. See Supplementary Material (Appendix 1) for the full questionnaire.

\section{Spirometry}

Spirometry was performed using the EasyOne ${ }^{\circledR}$ Air Spirometer and single use spirette (ndd Medical Technologies. Andover, USA). This ultrasound-based, portable device is the latest iteration of the handheld spirometer used in the BOLD studies. ${ }^{9}$ Spirometry was standardised using the 2005 American Thoracic Society (ATS)/European Respiratory Society (ERS) recommendations. ${ }^{8}$ Global Lung Initiative 2012 (GLI2012) "Other" reference ranges ${ }^{10}$ were chosen as values for the Solomon Islands are not yet available. Lower limit of normal (LLN) cut-offs were used to determine patterns of abnormality. We included spirometry data for analysis when at least one baseline forced expiratory manoeuvre met ATS/ERS quality criteria (Grade A-D). ${ }^{11}$ Patients who did not have acceptable spirometry were defined as having missing data and their spirometry was excluded. Obstruction was defined as FEV1/FVC ratio $<$ LLN, 
possible restriction as FEV1/FVC ratio $\geq$ LLN and FVC $<$ $80 \%$ of the predicted value. Significant bronchodilator responsiveness was defined as a $\geq 200 \mathrm{~mL}$ and $\geq 12 \%$ increase in absolute FEV1 or FVC. ${ }^{12}$ If a participant had an obstructed FEV1/FVC ratio, low FEV1, obstructive symptoms or a history of asthma, post-bronchodilator spirometry was performed 15 minutes after administration of $400 \mathrm{mcg}$ of inhaled salbutamol via metered dose inhaler and spacer. COPD was defined by a post-bronchodilator FEV1/FVC ratio below the lower limit of normal (LLN).

\section{Part 2. A Retrospective Hospital Audit}

A retrospective audit of Gizo Hospital emergency department (ED) records for the study period was conducted by two assessors (medical doctors). Patient records were selected at random and information was collected for the three month period March to May 2019 on patient demographics, presentation numbers and diagnosis.

\section{Statistical Analysis}

The values for the relevant patient characteristics and spirometry values are expressed as mean values. $T$-tests (unpaired) were used to compare numerical data, and Chi-square tests used to compare categorical data between groups. A p value of $<0.05$ was used to denote statistical significance. Z-scores were calculated by applying the GLI regression equation (Ethnicity was specified as "other"), using absolute measures of "FEV1", "FVC" and "FEV1/FVC" for the identifiable risk factors of smoking status, indoor wood fire exposure and the chewing of betel nut. The density (frequency) distribution of spirometry parameters for exposures were illustrated using a kernel density smoothing plot. The multiple linear regression analysis was conducted to examine the association between the risk factors and lung function, controlling for age and gender as covariates in the model. SAS (SAS Institute, Cary, NC, USA) was used to perform statistical analysis.

\section{Results}

\section{Part I. Population Based Prevalence Study Baseline Patient Characteristics}

A total of 104 participants underwent health questionnaire and spirometry. Overall, 60 participants were female and 44 were male. 11 were inpatients $(10.6 \%)$ and 93 outpatients $(89.4 \%)$. The average age was 46.9 (range 13-70 years). Both age groups reported high rates of hospital presentations in the previous 18 months $(>50 \%)$ but few subjects had been diagnosed with a respiratory condition such as pneumonia or asthma (11 reported previous pneumonia and five reported asthma). Respiratory medications were infrequently used with only six subjects currently using inhalers (four salbutamol and two beclomethasone). See Table 1 for full details.

\section{Smoking Status, Indoor Wood Fire Exposure and Betelnut Use}

Exposure to both cigarette smoke and indoor wood fire was common in this population. The overall smoking prevalence rate was $24.0 \%$ (current smokers) with $13.5 \%$ of people reporting a smoking history. Younger participants were more likely to be current smokers (43.3\% vs $16.2 \%)$. There was a high rate of regular indoor woodfire smoke exposure with $51.5 \%$ of subjects overall spending more than 10 hours per week close to a fire, usually for the purpose of cooking. The chewing of betel nut was common in this population, with over half of subjects reporting regular use (59.0\%). Betel nut chewing was even more frequent among younger people ( $80.8 \%$ versus $50.7 \%, \mathrm{p}=0.008$ ).

\section{Spirometry Results}

Of 104 subjects, 93 achieved acceptable spirometry and were included for analysis (Table 2). Overall, 3.2\% (3/93) demonstrated COPD with no significant difference between the two age groups. A significant bronchodilator response suggestive of possible asthma was demonstrated in $9.7 \%(9 / 93)$, with a predilection in the younger age group $(15.4 \%$ vs $7.5 \%)$. There was a high prevalence of restrictive spirometry, which was significantly more common in the older group $(31.3 \%$ vs $11.5 \%$ respectively, $\mathrm{p}=$ $0.05)$. Lastly, $12.9 \%$ (12/93) of participants exhibited the "Preserved Ratio Impaired Spirometry" (PRISm) pattern of FEV1/FVC ratio $\geq$ LLN and FEV1 $<$ LLN, ${ }^{13}$ without difference between groups.

The density (frequency) distribution of FEV1 (standardised Z-score) by smoking status (1A), degree of indoor woodfire exposure (1B), BMI (1C) and betel nut chewing (1D) is illustrated in Figure 1. Overall, the values seen in this Solomon Islands population are low. Although this may in part be explained by the reference values used, we see that abnormal lung function among the majority in this population is not explained by smoking (1A). The difference in FEV1 between the never smoker verse smoker is insignificant (mean difference $=-0.06,95 \%$ CI $(-0.54,0.42), p=0.79)$ and never smokers appear to have worse lung function. This suggests that factors other than 
Table I Baseline Patient Characteristics

\begin{tabular}{|c|c|c|c|c|}
\hline & & Total & Age $<40$ & Age $\geq \mathbf{4 0}$ \\
\hline \multicolumn{2}{|l|}{ Number } & $\begin{array}{l}\text { I04 total (II inpatients, } 93 \\
\text { outpatients) }\end{array}$ & $\begin{array}{l}30 \text { ( } 2 \text { inpatients, } 28 \\
\text { outpatients) }\end{array}$ & $\begin{array}{l}74 \text { (9 inpatients, } 65 \\
\text { outpatients) }\end{array}$ \\
\hline \multicolumn{2}{|l|}{ Average Age } & $46.9( \pm 13.8)$ & $30.2( \pm 7.1)$ & $53.7( \pm 9.4)$ \\
\hline \multicolumn{2}{|l|}{ Sex } & 60 female, 44 male & 13 female, 17 male & 47 female, 27 male \\
\hline \multicolumn{2}{|l|}{ Average BMI } & $29.4( \pm 5.4)$ & $27.2( \pm 4.7)$ & $30.3( \pm 5.5)$ \\
\hline \multirow{2}{*}{\multicolumn{2}{|c|}{ Reported Respiratory History }} & 5 Asthma & I asthma & 4 asthma \\
\hline & & II Pneumonia & 5 pneumonia & 6 pneumonia \\
\hline \multirow{2}{*}{\multicolumn{2}{|c|}{ Respiratory Medications }} & 4 salbutamol & \multirow[t]{2}{*}{ None } & 4 salbutamol \\
\hline & & 2 Beclomethasone & & 2 Beclomethasone \\
\hline \multicolumn{2}{|l|}{ Hospital since 2018} & $60 / 96(62.5 \%)$ & I4/26 (53.9\%) & $46 / 70(65.7 \%)$ \\
\hline \multicolumn{2}{|l|}{ Chews Betelnut } & $56 / 95(59.0 \%)$ & $21 / 26(80.8 \%)$ & $35 / 69(50.7 \%)$ \\
\hline Smoking status & $\begin{array}{l}\text { Never } \\
\text { Ex-smoker } \\
\text { Current }\end{array}$ & $\begin{array}{l}65 / 104(62.5 \%) \\
14 / 104(13.5 \%) \\
25 / 104(24.0 \%)\end{array}$ & $\begin{array}{l}13 / 30(43.3 \%) \\
4 / 30(13.3 \%) \\
13 / 30(43.3 \%)\end{array}$ & $\begin{array}{l}52 / 74(70.3 \%) \\
10 / 74(13.5 \%) \\
12 / 74(16.2 \%)\end{array}$ \\
\hline Pack years & $\begin{array}{l}<10 \\
10-20 \\
>20\end{array}$ & $\begin{array}{l}12 / 39(30.8 \%) \\
14 / 39(35.9 \%) \\
13 / 39(33.3 \%)\end{array}$ & $\begin{array}{l}7 / 17(41.2 \%) \\
7 / 17(41.2 \%) \\
3 / 17(17.7 \%)\end{array}$ & $\begin{array}{l}5 / 22(22.7 \%) \\
7 / 22(31.8 \%) \\
10 / 22(45.5 \%)\end{array}$ \\
\hline $\begin{array}{l}\text { Indoor wood fire } \\
\text { exposure }\end{array}$ & $\begin{array}{l}\text { None } \\
\text { Occasional (<10hrs/week) } \\
\text { Regular ( }>\text { |Ohrs/week) }\end{array}$ & $\begin{array}{l}27 / 103(26.2 \%) \\
23 / 103(22.3 \%) \\
53 / 103(51.5 \%)\end{array}$ & $\begin{array}{l}12 / 29(41.4 \%) \\
6 / 29(20.7 \%) \\
11 / 29(37.9 \%)\end{array}$ & $\begin{array}{l}15 / 74(20.3 \%) \\
17 / 74(23.0 \%) \\
42 / 74(56.8 \%)\end{array}$ \\
\hline
\end{tabular}

Notes: Inpatients: participants admitted to hospital. Outpatients: participants not admitted to hospital.

Table 2 Spirometry Results

\begin{tabular}{|c|c|c|c|c|}
\hline & Total & Age $<40$ & Age $\geq \mathbf{4 0}$ & p-value \\
\hline Acceptable baseline Spirometry performed & $\begin{array}{c}93 \text { (II inpatient, } 82 \\
\text { outpatient) }\end{array}$ & $\begin{array}{c}26 \text { ( } 2 \text { inpatient, } 24 \\
\text { outpatient) }\end{array}$ & $\begin{array}{c}67 \text { (9 inpatient, } 58 \\
\text { outpatient) }\end{array}$ & \\
\hline Best FEVI (\%) & $81.3( \pm 17.0)$ & $86.0( \pm 14.6)$ & $79.5( \pm 17.7)$ & 0.10 \\
\hline Best FEVI (L) & $2.29( \pm 0.72)$ & $2.82( \pm 0.64)$ & $2.08( \pm 0.64)$ & \\
\hline Best FVC (\%) & $83.6( \pm 15.2)$ & $89.1( \pm \mid 3.0)$ & $81.5( \pm 15.5)$ & 0.03 \\
\hline Best FVC (L) & $2.87( \pm 0.82)$ & $3.45( \pm 0.72)$ & $2.64( \pm 0.74)$ & \\
\hline FEVI/FVC & $79.5( \pm 8.6)$ & $81.9( \pm 7.6)$ & $78.5( \pm 8.9)$ & 0.10 \\
\hline COPD $^{a}$ & $3 / 93(3.2 \%)$ & $1 / 26(2.8 \%)$ & $2 / 67(3.0 \%)$ & 0.83 \\
\hline Bronchodilator responsiveness ${ }^{\mathrm{b}}$ & $9 / 93(9.7 \%)$ & $4 / 26(15.4 \%)$ & $5 / 67(7.5 \%)$ & 0.25 \\
\hline Possible restriction $^{c}$ & $24 / 93(25.8 \%)$ & $3 / 26(11.5 \%)$ & $21 / 67(31.3 \%)$ & 0.05 \\
\hline Preserved Ratio Impaired Spirometry (PRISm) ${ }^{d}$ & $12 / 93(12.9 \%)$ & $3 / 26(11.5 \%)$ & $9 / 67$ (13.4\%) & 0.81 \\
\hline
\end{tabular}

Notes: ${ }^{2}$ COPD: defined as post-bronchodilator FEVI/FVC ratio < LLN. ${ }^{\mathrm{b} B r o n c h o d i l a t o r ~ r e s p o n s i v e n e s s: ~ d e f i n e d ~ a s ~ s i g n i f i c a n t ~ b r o n c h o d i l a t o r ~ r e s p o n s e ~ i n ~ F E V I ~ o r ~ F V C . ~}$

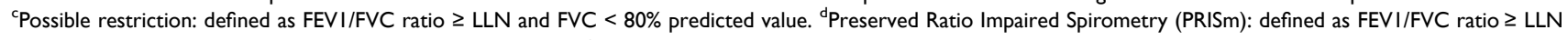
and FEVI < LLN. Inpatients: participants admitted to hospital. Outpatients: participants not admitted to hospital.

Abbreviations: FEVI, forced expiratory volume-one second; FVC, forced vital capacity; LLN, lower limit of normal. 

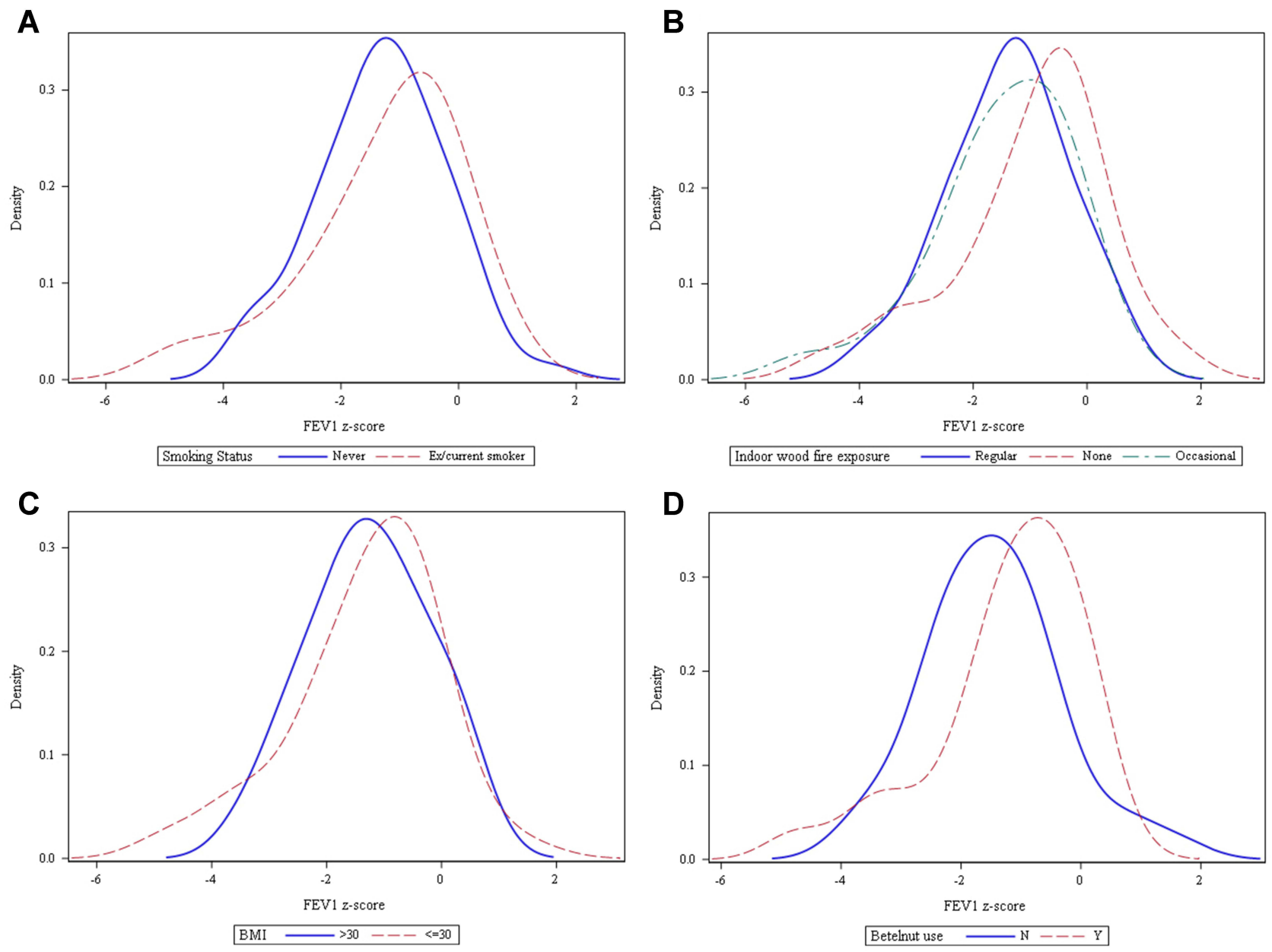

Figure I Density (frequency) distribution of FEVI by smoking status (A), degree of indoor woodfire exposure (B), BMI (C) and betel nut use (D).

smoking may be important contributors to abnormal lung function in this population.

Based on the multiple linear regression model controlling for age and gender, similarly there was no significant association observed between FEV1 Z-score and smoking $(p=0.98)$. Furthermore, there was no significant association observed between FEV1 Z-score and indoor wood fire $(\mathrm{p}=0.37)$, betel nut chewing $(\mathrm{p}=0.37)$ and BMI $(\mathrm{p}=0.57)$. There was also no significant association between other lung function measures (FVC and FEV1/FVC) and the four risk factors investigated ( $\mathrm{p}$ value ranges from 0.26 to 0.98 ). Frequency distributions for FVC and FEV1/FVC are shown in Figures 2 and 3.

\section{Part 2. Hospital Presentation Audit}

ED presentations are divided into those seen by an Emergency Doctor and "fast track" patients - usually lessacute patients managed by nursing staff. Patients selftriage to fast track. All Emergency patients are seen by an emergency nurse who can prescribe medications. Referral to an Emergency Doctor is decided by the nursing staff treating the patient. ED presentation demographics are shown in Table 3.

After being assessed by a nurse in "fast-track", 18.0\% of patients were subsequently referred to an Emergency Doctor. The majority of patients seen in the ED presented with a respiratory condition or fever/viral illness. Unfortunately, due to poor documentation, there was not enough data to sub-classify respiratory conditions. There was no spirometry or peak flow readings as no equipment was available. An analysis of presenting illnesses/diagnoses are seen in Figures 4 and 5.

After assessment by an Emergency Doctor, 51.0\% of patient records reviewed were discharged and $46.4 \%$ of patients were admitted to hospital for further management. Three acutely unwell patients were referred to the National Referral Hospital in Honiara. Documentation was unclear for 2 patients. 

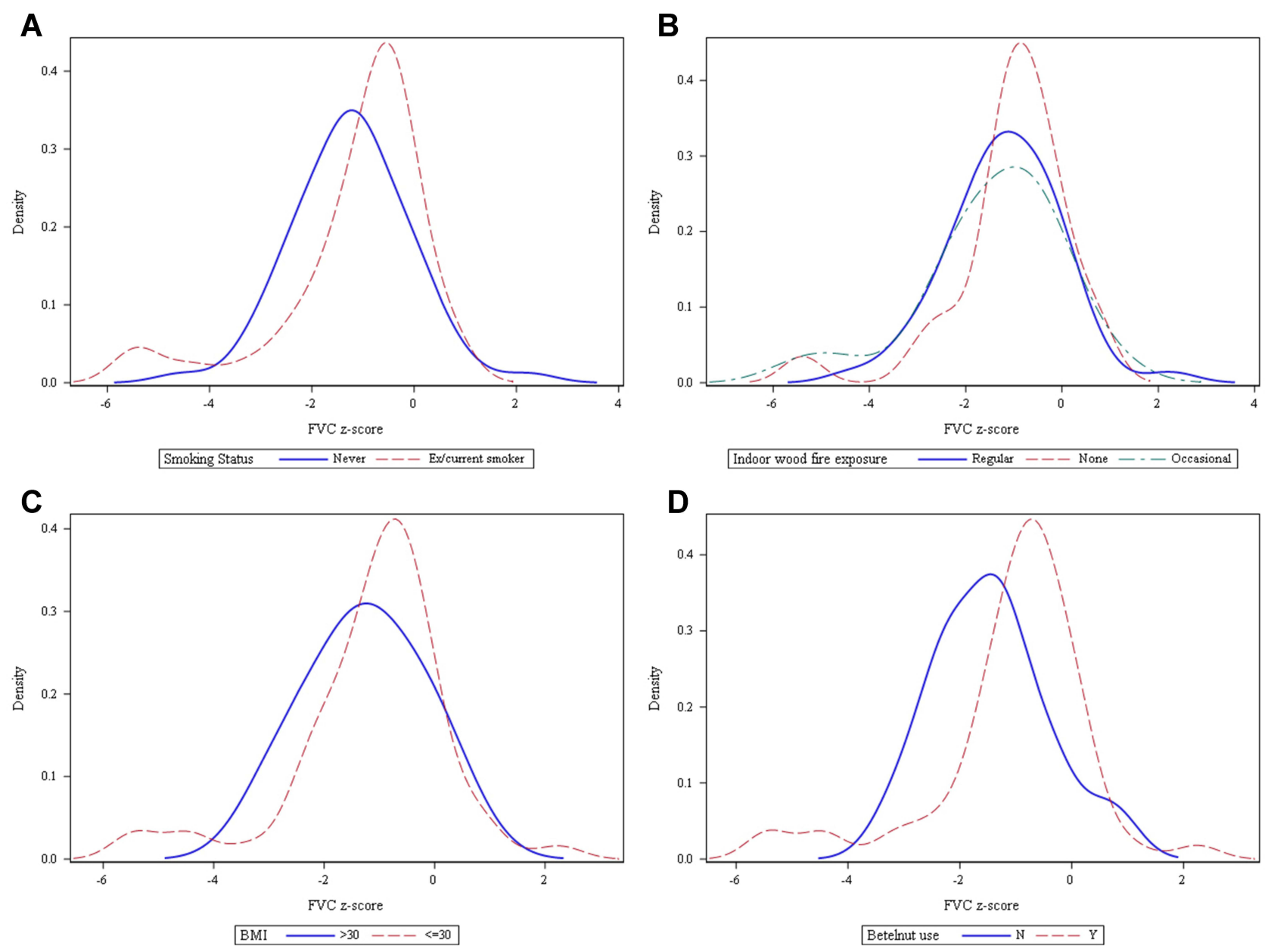

Figure 2 Density (frequency) distribution of FVC by smoking status (A), degree of indoor woodfire exposure (B), BMI (C) and betel nut use (D).

\section{Discussion}

This study is the first in over 35 years to attempt to quantify the burden of obstructive lung disease in the Solomon Islands via the use of spirometric readings. Only one previous study looked specifically at the relationship of smoking and lung function in a Solomon Island population, ${ }^{14}$ however did not include post-bronchodilator spirometry, nor quantification of smoking or biomass fuel exposure.

Currently there is very limited data on the prevalence of airways disease in the Solomon Islands. The Global Burden of Disease (GBD) 2010 Study ranked COPD and asthma 9th and 28th respectively for overall disabilityadjusted years of life lost (DALYs) globally. ${ }^{15}$ For the Oceania region (comprising Fiji, Kiribati, Marshall Islands, Micronesia, Papua New Guinea, Samoa, Solomon Islands, Tonga and Vanuatu) COPD is lower at 18th and asthma much higher at 8th. The most recent 2015
GBD study states that no prevalence data for COPD was available for the Oceania region and that data on asthma prevalence relies on a reported diagnosis and symptoms. ${ }^{16}$ At the time of writing, the Burden of Obstructive Lung Disease (BOLD) study, an ongoing global initiative at over 40 sites across the world diagnosing COPD via spirometry readings (FEV1/FVC $<70$ ), also does not include data on the Solomon Islands. ${ }^{9}$

This study reports the overall prevalence of COPD in the Solomon Islands at 3.2\%. By comparison, the most recent data available from the 2017 GBD study shows a global allage COPD prevalence of $4.1 \%$ (3.7-4.5\%). ${ }^{15,17,18}$ Recent estimates from the BOLD study put the global COPD prevalence at $10.1 \%,{ }^{19}$ however with wide variations between countries. We documented 9 participants (9.6\%) with a significant bronchodilator response suggestive of asthma, with a non-significant trend towards a higher prevalence in the younger population. This was more than the number of 
A

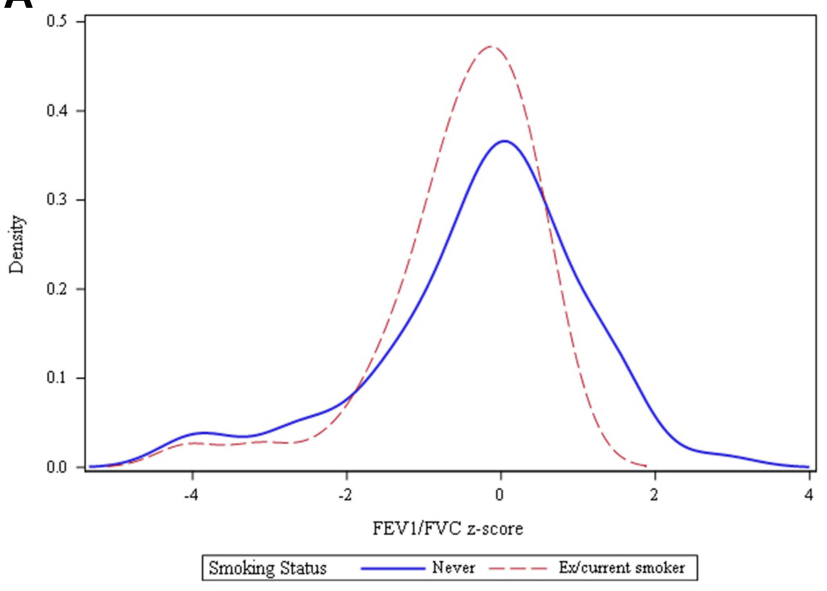

C

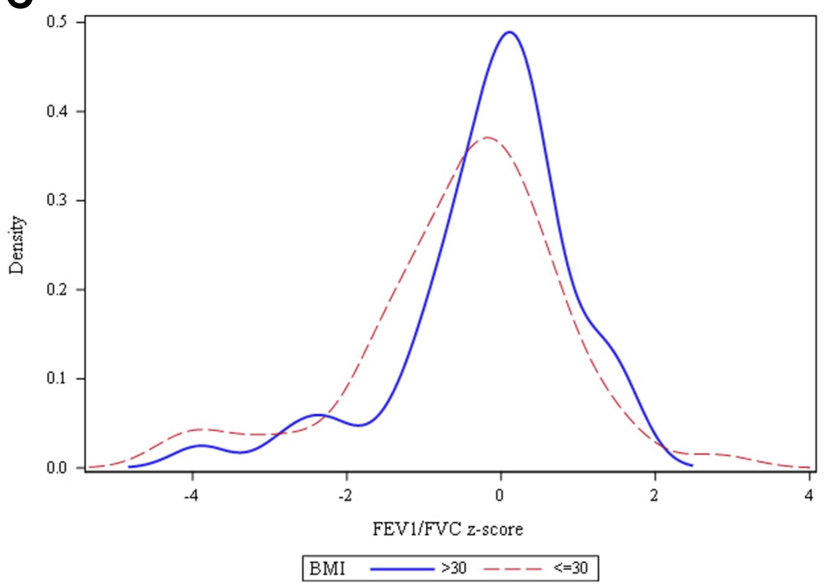

B

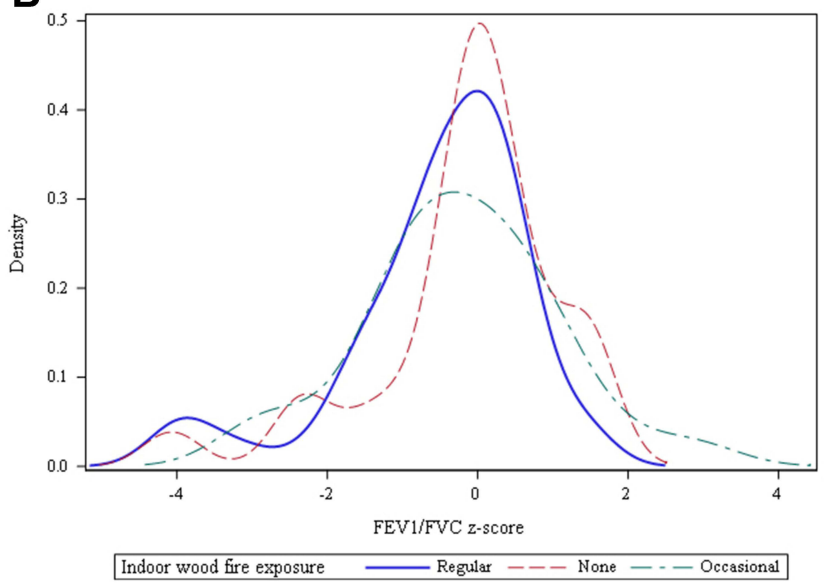

D

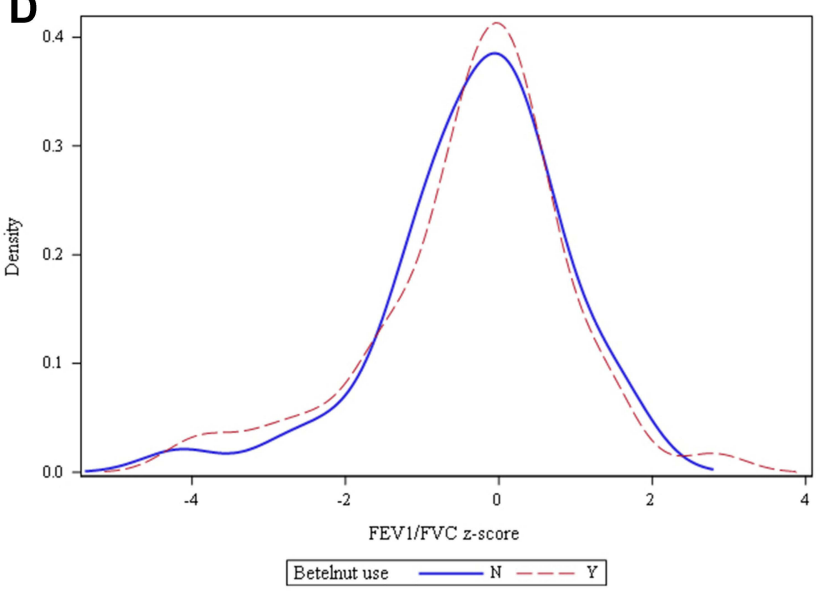

Figure 3 Density (frequency) distribution of FEVI/FVC by smoking status (A), degree of indoor woodfire exposure (B), BMI (C) and betel nut use (D).

self-reported cases of asthma (5), although only one of these self-reported cases demonstrated significant bronchodilator response at the time of testing. By comparison, the 2017 GBD global all-age asthma prevalence was much lower at $3.70 \%$ (3.28-4.13\%). 2017 GBD DALY rates for asthma were also higher for middle to low socio-demographic index (SDI) countries compared to their high-SDI counterparts. ${ }^{16}$ The preserved ratio impaired spirometry
(PRISm) pattern of FEV1/FVC ratio $\geq$ LLN and FEV1 < LLN has been shown to be associated with increased symptoms, exacerbations and mortality when compared with normal spirometry. ${ }^{13,20}$ Furthermore, PRISm appears to be representative of a transitional state with $25-49 \%$ of individuals with PRISm progressing on to develop classic airflow obstruction. ${ }^{13,21}$ Our PRISm prevalence of $12.9 \%$ appears consistent with previous documented prevalences

Table 3 Emergency Patient Demographics

\begin{tabular}{|l|l|l|}
\hline & "Fast Track" Patients & Emergency Doctor Patients \\
\hline Average Age & 23.9 years (range I-7I) & 34.0 years (range I-82) \\
\hline Total & $120(62$ female, 57 male) & $136(77$ female, 55 male) \\
\hline Sex not Recorded & $\mathrm{I}(0.8 \%)$ & $4(2.9 \%)$ \\
\hline Paediatric Patients $(<16$ years) & $48(40.0 \%)$ & $36(26.5 \%)$ \\
\hline Age $>65$ years & $\mathrm{I}(0.8 \%)$ & $13(10.0 \%)$ \\
\hline
\end{tabular}

Notes: Fast Track: "fast track" patients - less-acute patients that are managed by nursing staff. Patients self-triage to fast track. 


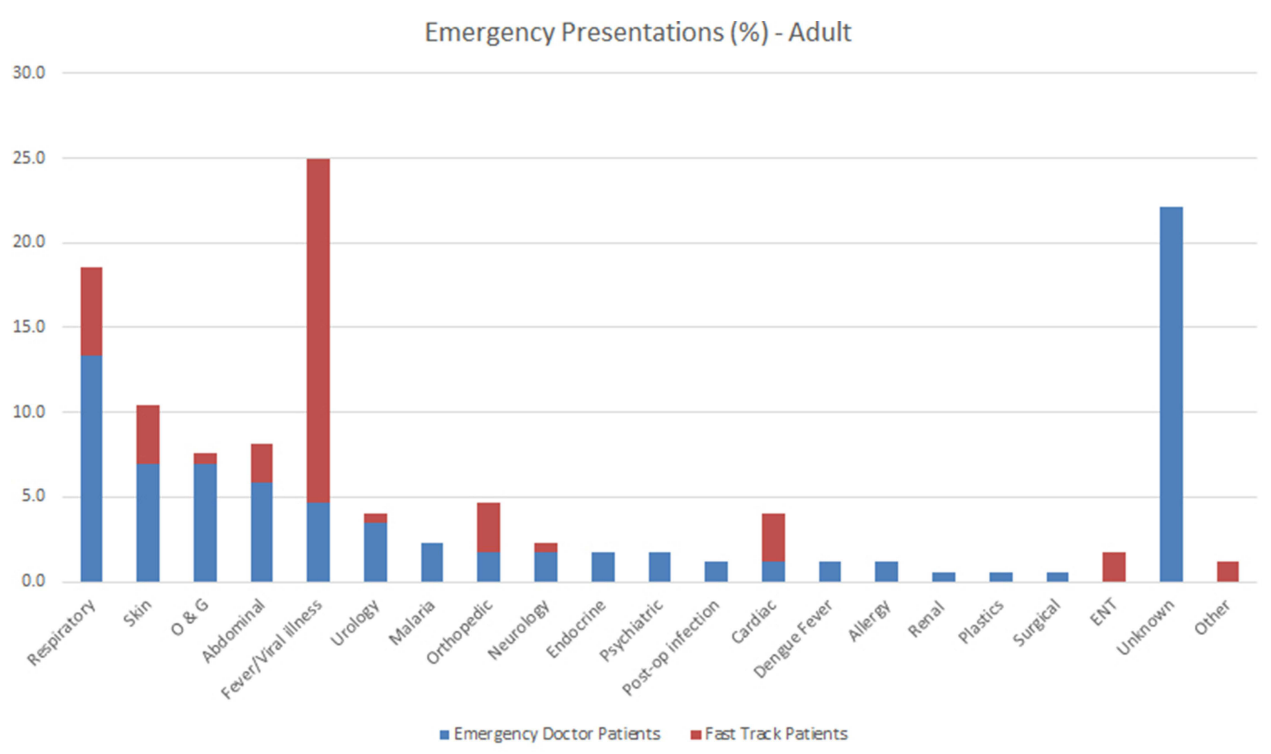

Figure 4 Adult patients seen in emergency by presentation (\%). Note some adult patients had more than one presenting issue.

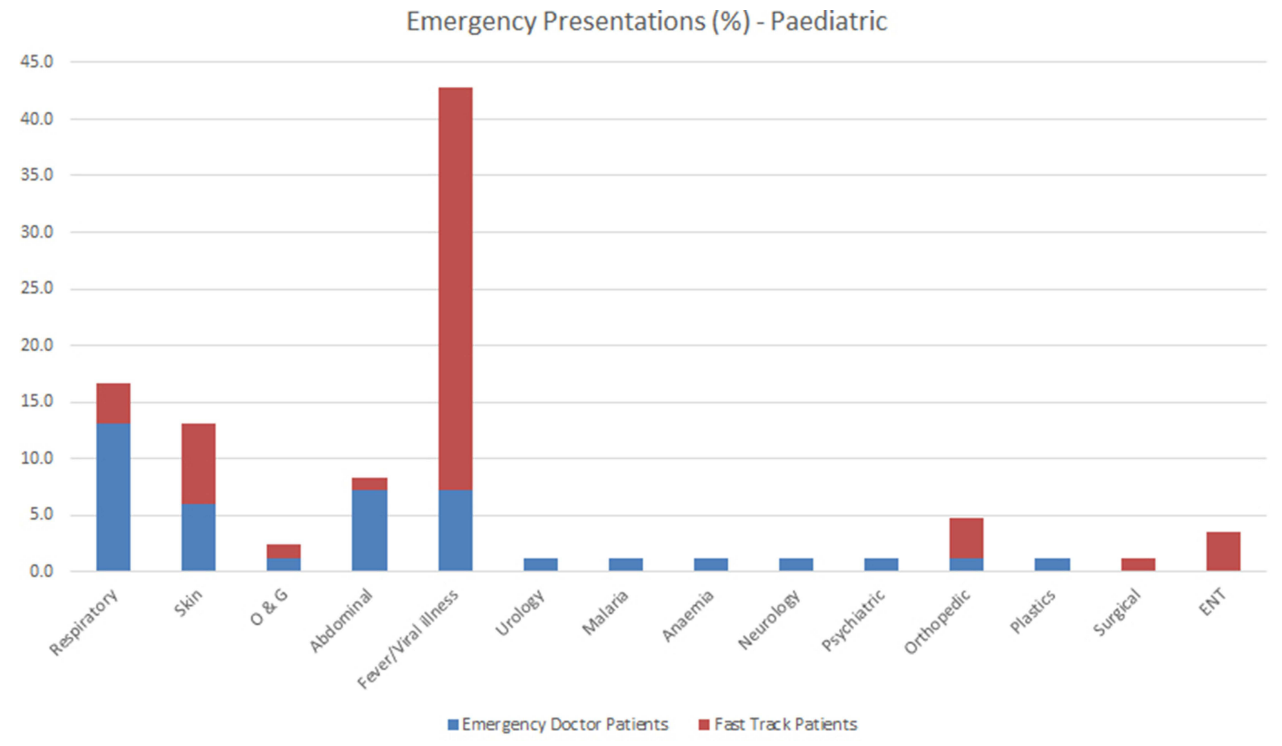

Figure 5 Paediatric patients seen in emergency by presentation (\%).

of $\sim 12 \%,{ }^{7,13,22}$ although more recent estimates in an American population suggest an even higher PRISm prevalence of $17-24 \%{ }^{23}$ Thus, these patients may represent a group with significant risk of progression to COPD.

Despite the apparently high prevalence of obstructive and bronchodilator-responsive lung disease in the Solomon Islands there appears to be under-diagnosis and under-prescribing of essential inhaler therapies. Results from our health questionnaire showed that only four patients were actively using a salbutamol inhaler, and two patients were using inhaled beclomethasone. This is despite all medications being provided free of charge to Solomon Islanders accessing the public health system. ${ }^{5}$ Furthermore, our study results showed a high rate of recent hospital presentations amongst the surveyed population in Gizo (62.5\%). A majority these presentations were respiratory in nature, although this high hospital presentation could be the result of limited nearby healthcare options.

We specifically assessed risk factors for chronic respiratory disease with including cigarette smoking and exposure to biomass fuel from indoor wood fire ovens. Previous BOLD data confirms tobacco smoke as the most 
important cause of COPD worldwide, ${ }^{24}$ with indoor air pollutants such as biomass fuels used for cooking possibly more significant in low and middle-income countries. ${ }^{24,25}$ The rate of active smokers in our sampled population was high at $24.0 \%$, with a higher rate in the younger age group. This is lower than earlier data published by the WHO which suggested an even higher prevalence of smoking in the Solomon Islands approaching 40\%. ${ }^{2,26}$ Exposure to biomass fuels in the form of wood fire ovens appears to very common in the Solomon Islands. Our results suggested that $51.5 \%$ of individuals included were exposed to regular ( $>10$ hours per week) indoor wood fire for cooking. Byerley et $\mathrm{al}^{14}$ observed lower FEV1 values in Solomon Island females despite women having a lower prevalence of smoking and suggested that exposure to wood fire ovens may be contributing, however they did not attempt to quantify such exposure. Our results, however, are congruent with the BOLD results which also found no association between airflow obstruction and use of solid fuels for cooking or heating. ${ }^{27}$ The high prevalence of restricted spirometry seen in our study (26.60\%) was well above the $14.2 \%$ global rate seen from BOLD study data. ${ }^{28}$ We acknowledge the predictive equations and reference values used may have overestimated expected spirometric values for our population.

Lastly, the chewing of betel nut, the seed of the Areca palm, is associated with a number of adverse health effects including oral and oesophageal malignancies, myocardial infarction, cardiac arrhythmias, hepatotoxicity, obesity, type 2 diabetes, metabolic syndrome, hypothyroidism, infertility, and adverse reproductive outcomes. ${ }^{29}$ Small case series have shown an association between betel nut, bronchoconstriction and asthma. ${ }^{30,31}$ Our results show that almost $60 \%$ of participants actively chewed betel nut regularly, with significantly higher rates in the younger age group, indicating an important and often under-recognised risk factor for poor health in the Solomon Islands and surrounding Pacific nations.

This study has some limitations. The relative small number of participants in our study may mean the results do not adequately reflect the population as a whole. The nature of our study meant passers-by and participants were able to see what was happening which may have introduced unintentional selection or participation bias. However, our sampling strategy aimed to include a wide cross-section of the island's population and the 104 people included in this study represents almost $2 \%$ of the entire population of the island. Our study was not blinded, assessors and participants were informed of their spirometry findings. However, the primary outcome measure (spirometry) was objective and so blinding should not have affected these results. In collecting data on previous respiratory diagnoses, we did not report COPD/emphysema nor was this specifically asked, due to the lack of understanding of these terms in this population. We documented participants with bronchodilator responsiveness as "suggestive of possible asthma" as an asthma diagnosis cannot be confidently confirmed by bronchodilator responsiveness alone. Lastly, as no previous spirometric reference values were available for the region/country, we used the ethnicity value "Other" as defined in the Global Lung Initiative GLI 2012 reference equations, ${ }^{10}$ which may not adequately reflect the population. We also used the LLN for FEV1/FVC obstruction rather than an absolute value of $<0.7$. This was done as participants had a young average age (46.9 years) with a wide range and thus a set value would likely underestimate the incidence of obstructive spirometry.

In conclusion, we have demonstrated a high burden of obstructive and bronchodilator-responsive lung disease in the Solomon Islands. There appears to be an increased prevalence of asthma over COPD and while there are high smoking rates, lung function appears to be better in smokers compared to non-smokers. Thus, factors other than smoking appear important for abnormal lung function in this population. These may include wood fire smoke exposure for cooking, increased BMI, previous respiratory infections including tuberculosis and bacterial pneumonia and importantly, untreated asthma. With respiratory symptoms common amongst hospital ED presentations it is possible that under diagnosed and under treated asthma in this population is an important contributor to poor lung health in the Solomon Islands. We believe that future studies that assess the effect of better outpatient asthma diagnosis and treatment on ED presentations are important in improving the lung health of other Pacific Island populations.

\section{Summary at a Glance}

We present data from a two-part study assessing respiratory patient health in Gizo, Solomon Islands. Using both patient data and spirometry measurements, we were able to measure the prevalence of obstructive lung disease, the effect of patient demographics and known exposures. We describe and reflect on current management practices. 


\section{Disclosure}

Dr Anthony Byrne provided educational speaking event for GSK, outside the submitted work. The authors have no other conflicts of interest to declare.

\section{References}

1. Solomon Islands Government. Solomon Islands national statistics office. Available from: https://www.statistics.gov.sb/. Accessed December, 2019.

2. Kessaram T, McKenzie J, Girin N, et al. Noncommunicable diseases and risk factors in adult populations of several Pacific Islands: results from the WHO STEPwise approach to surveillance. Aust N Z J Public Health. 2015;39(4):336-343. doi:10.1111/17536405.12398

3. Solomon Islands National Statistics Office, Solomon Islands Ministry of Health and Medical Services and the Pacific Community. Solomon Islands Demographic and Health Survey 2015; June, 2017.

4. Byrne AL, Marais BJ, Mitnick CD, Lecca L, Marks GB. Tuberculosis and chronic respiratory disease: a systematic review. Int J Infect Dis. 2015;32:138-146. doi:10.1016/j.ijid.2014.12.016

5. Hodge N, Slatyer B, Skiller L. Solomon Islands Health System Review. Vol. 5(1). World Health Organization, Regional Office for the Western Pacific; 2015:2015.

6. WHO and the Solomon Islands Ministry of Health. Health Service Delivery Profile. Solomon Islands; 2012.

7. Global Initiative for Chronic Obstructive Lung Disease (GOLD). Global Strategy for the Diagnosis, Management, and Prevention of Chronic Obstructive Pulmonary Disease (2019 Report); 2019.

8. Miller MR, Hankinson J, Brusasco V, et al. Standardisation of spirometry. Eur Respir J. 2005;26(2):319-338. doi:10.1183/ 09031936.05.00034805

9. Buist AS, Vollmer WM, Sullivan SD, et al. The Burden of Obstructive Lung Disease initiative (BOLD): rationale and design. COPD. 2005;2(2):277-283. doi:10.1081/COPD-57610

10. Quanjer PH, Stanojevic S, Cole TJ, et al. Multi-ethnic reference values for spirometry for the 3-95-yr age range: the global lung function 2012 equations. Eur Respir J. 2012;40(6):1324-1343. doi:10.1183/09031936.00080312

11. Graham BL, Steenbruggen I, Miller MR, et al. Standardization of spirometry 2019 update. An official American thoracic society and European respiratory society technical statement. Am J Respir Crit Care Med. 2019;200(8):e70-e88. doi:10.1164/rccm.201908-1590ST

12. Pellegrino R, Viegi G, Brusasco V, Crapo RO, Burgos F, Casaburi R. Interpretative strategies for lung function tests. Eur Respir J. 2005;26 (5):948-968. doi:10.1183/09031936.05.00035205

13. Wan ES, Fortis S, Regan EA, et al. Longitudinal phenotypes and mortality in preserved ratio impaired spirometry in the COPDGene Study. Am J Respir Crit Care Med. 2018;198(11):1397-1405. doi:10.1164/rccm.201804-0663OC

14. Byerley DM, Weitz CA, Richards F. Smoking and pulmonary function in five Solomon Island populations. Am J Phys Anthropol. 1992;89(1):11-17. doi:10.1002/ajpa.1330890103

15. Murray CJL, Vos T, Lozano R, et al. Disability-adjusted life years (DALYs) for 291 diseases and injuries in 21 regions, 1990-2010: a systematic analysis for the Global Burden of Disease Study 2010. Lancet. 2012;380(9859):2197-2223. doi:10.1016/S0140-6736(12) 61689-4
16. Collaborators GBDCRD. Global, regional, and national deaths, prevalence, disability-adjusted life years, and years lived with disability for chronic obstructive pulmonary disease and asthma, 1990-2015: a systematic analysis for the Global Burden of Disease Study 2015. Lancet Respir Med. 2017;5(9):691-706. doi:10.1016/S2213-2600(17) 30293-X

17. Disease GBD, Injury I, Prevalence C. Global, regional, and national incidence, prevalence, and years lived with disability for 354 diseases and injuries for 195 countries and territories, 1990-2017: a systematic analysis for the Global Burden of Disease Study 2017. Lancet. 2018;392(10159):1789-1858. doi:10.1016/S0140-6736(18) 32279-7

18. Global Burden of Disease Collaborative Network, Institute for Health Metrics and Evaluation (IHME). Global Burden of Disease Study 2017 results. Available from: http://ghdx.healthdata.org/gbd-resultstool. Accessed October 29, 2021.

19. Buist AS, McBurnie MA, Vollmer WM, et al. International variation in the prevalence of COPD (the BOLD Study): a population-based prevalence study. Lancet. 2007;370(9589):741-750. doi:10.1016/ S0140-6736(07)61377-4

20. Wan ES, Castaldi PJ, Cho MH, et al. Epidemiology, genetics, and subtyping of preserved ratio impaired spirometry (PRISm) in COPDGene. Respir Res. 2014;15(1):89. doi:10.1186/s12931-0140089-y

21. Wijnant SRA, De Roos E, Kavousi M, et al. Trajectory and mortality of preserved ratio impaired spirometry: the Rotterdam Study. Eur Respir J. 2020;55(1):1901217. doi:10.1183/13993003.01217-2019

22. Guerra S, Sherrill DL, Venker C, Ceccato CM, Halonen M, Martinez FD. Morbidity and mortality associated with the restrictive spirometric pattern: a longitudinal study. Thorax. 2010;65 (6):499-504. doi:10.1136/thx.2009.126052

23. Schwartz A, Arnold N, Skinner B, et al. Preserved ratio impaired spirometry in a spirometry database. Respir Care. 2021;66(1):58-65. doi: $10.4187 /$ respcare. 07712

24. Mannino DM, Buist AS. Global burden of COPD: risk factors, prevalence, and future trends. Lancet. 2007;370(9589):765-773. doi:10.1016/S0140-6736(07)61380-4

25. Lopez A, Mathers C, Ezzati M, Jamison D, Murray C. Global Burden of Disease and Risk Factors. Vol. 2006. Washington (DC): The International Bank for Reconstruction and Development/The World Bank; 2006.

26. Solom Islands Government, Western Pacific Region. Solomon Islands NCD Risk Factors STEPS Report; 2006.

27. Amaral AFS, Patel J, Kato BS, et al. Airflow obstruction and use of solid fuels for cooking or heating: BOLD results. Am J Respir Crit Care Med. 2018;197(5):595-610. doi:10.1164/rccm.201701-0205OC

28. Mannino DM, McBurnie MA, Tan W, et al. Restricted spirometry in the Burden of Lung Disease Study. Int J Tuberc Lung Dis. 2012;16 (10):1405-1411. doi:10.5588/ijtld.12.0054

29. Garg A, Chaturvedi P, Gupta PC. A review of the systemic adverse effects of areca nut or betel nut. Indian J Med Paediatr Oncol. 2014;35(1):3-9. doi:10.4103/0971-5851.133702

30. Sekkadde Kiyingi K, Saweri A. Betelnut chewing causes bronchoconstriction in some asthma patients. $P N G$ Med J. 1994;37 (2):90-99.

31. Taylor RF, al-Jarad N, John LM, Conroy DM, Barnes NC. Betel-nut chewing and asthma. Lancet. 1992;339(8802):1134-1136. doi:10.1016/0140-6736(92)90732-i 


\section{Publish your work in this journal}

The International Journal of COPD is an international, peer-reviewed journal of therapeutics and pharmacology focusing on concise rapid reporting of clinical studies and reviews in COPD. Special focus is given to the pathophysiological processes underlying the disease, intervention programs, patient focused education, and self management

protocols. This journal is indexed on PubMed Central, MedLine and CAS. The manuscript management system is completely online and includes a very quick and fair peer-review system, which is all easy to use. Visit http://www.dovepress.com/testimonials.php to read real quotes from published authors.

Submit your manuscript here: https://www.dovepress.com/international-journal-of-chronic-obstructive-pulmonary-disease-journal 